\title{
Fed-batch fermentation of GM-CSF-producing glycoengineered Pichia pastoris under controlled specific growth rate
}

\author{
Pieter P Jacobs ${ }^{1,2,3^{*}}$, Mehmet Inan ${ }^{4,7}$, Nele Festjens ${ }^{1,2}$, Jurgen Haustraete ${ }^{2,5}$, Annelies Van Hecke ${ }^{1,2}$, \\ Roland Contreras ${ }^{1,2}$, Michael M Meagher ${ }^{4}$, Nico Callewaert ${ }^{1,6^{*}}$
}

\begin{abstract}
Background: Yeast expression systems with altered N-glycosylation are now available to produce glycoproteins with homogenous, defined N-glycans. However, data on the behaviour of these strains in high cell density cultivation are scarce.

Results: Here, we report on cultivations under controlled specific growth rate of a GlycoSwitch-Man5 Pichia pastoris strain producing Granulocyte-Macrophage Colony-Stimulating Factor (GM-CSF) at high levels (hundreds of milligrams per liter). We demonstrate that homogenous $\mathrm{Man}_{5} \mathrm{GlCNAC}_{2} \mathrm{~N}$-glycosylation of the secreted proteins is achieved at all specific growth rates tested.
\end{abstract}

Conclusions: Together, these data illustrate that the GlycoSwitch-Man5 P. pastoris is a robust production strain for homogenously N-glycosylated proteins.

\section{Background}

Despite the availability of five classes of heterologous protein production platforms (bacteria, yeasts, plants, insect cells, and mammalian cells), more than $50 \%$ of currently marketed biopharmaceuticals are produced in mammalian cell lines [1]. This is in part due to the inability of the remaining four classes to modify glycoproteins with human-like oligosaccharides. This is of importance since protein-bound glycans influence circulation half-life, tissue distribution, and biological activity. In addition, they may be immunogenic. Therefore, engineering of the glycosylation pathway of most currently used heterologous protein expression systems is an active field of research [2].

Although many biopharmaceutical companies have been experimenting for many years with the methylotrophic yeast $P$. pastoris as an expression system for the production of therapeutic proteins, the first Pichia product approval by the FDA was announced only very

\footnotetext{
* Correspondence: pjacobs@rics.bwh.harvard.edu; nico.callewaert@dmbr.vibUGent.be

'Unit for Molecular Glycobiology, Department for Molecular Biomedical Research, VIB, Ghent, Belgium

Full list of author information is available at the end of the article
}

recently (KALBITOR, Dyax Corp.). This now established regulatory approval pathway, together with the recent availability of glycoengineered strains that produce heterologous proteins predominantly as single glycoforms $[3,4]$, should pave the way for future biopharmaceutical production. As a result, batch-to-batch variability is reduced and downstream processing is facilitated due to increased product homogeneity. Moreover, pharmacokinetic and pharmacodynamic properties can be more easily controlled and fine-tuned, as has been shown for human IgG [5] and rat erythropoietin [3].

Over the past decade, we have created several glycoengineered $P$. pastoris strains each capable of modifying its glycoproteins with predominantly one defined N-glycan structure $[2,4,6,7]$. Recently, we have started to explore their behavior under controlled bioreactor conditions. The primary goal of these experiments was to determine the robustness of our strains in terms of $\mathrm{N}$-glycan homogeneity and product yield when subjected to different growth conditions. In this study, we have used a glycoengineered $P$. pastoris strain capable of modifying its glycoproteins with $\mathrm{Man}_{5} \mathrm{GlcNAc}_{2} \mathrm{~N}$-glycans to produce murine granulocyte-macrophage colonystimulating factor (GM-CSF) as a test protein. 
GM-CSF belongs to a family of colony-stimulating factors that regulate proliferation and differentiation of hematopoietic cells [8]. In response to inflammatory stimuli, GM-CSF is released by various cell types including T lymphocytes, macrophages, fibroblasts and endothelial cells $[9,10]$. GM-CSF then activates and enhances the production and survival of neutrophils, eosinophils, and macrophages [11].

In the clinic, GM-CSF is used for treatment of neutropenia and aplastic anemia following chemotherapy and greatly reduces the risk of infection associated with bone marrow transplantation. Its utility in myeloid leukemia treatment and as a vaccine adjuvant is well established $[12,13]$. The two GM-CSF analogs currently on the market differ from each other and from the native protein on two points, primary structure and glycosylation status. Sargramostim is produced in S. cerevisiae. Like native GM-CSF, it has 127 amino acids and is glycosylated but differs from native GM-CSF in molecular mass and in the substitution of leucine for proline at position 23 . Therapeutic GM-CSF expressed in Escherichia coli is not glycosylated, has six fewer amino acids than the native protein, and an extra methionine at position 1 [14]. E. coli-produced GM-CSF is also known as Molgramostim (marketed as Leucomax ${ }^{\bullet}$ by Schering-Plough), but was never approved for use in the United States by the FDA because it was associated with a higher incidence of adverse effects than Sargramostim [14]. The latter product is produced in S. cerevisiae and is marketed as Leukine $^{\circ}$ (Bayer Healthcare Pharmaceuticals).

Murine GM-CSF (mGM-CSF) is a 124 amino acid glycoprotein with an apparent molecular weight of 14-33 $\mathrm{kDa}$ [15]. It contains two intramolecular disulfide bonds (Cys51-93, Cys85-118), two potential N-glycosylation sites (Asn66 and 75) as well as sites of O-glycosylation [16]. The protein is very resistant to denaturing and proteolytic conditions [15]. Non-glycosylated GM-CSF is fully biologically active and in fact is up to 10 times more potent than the fully glycosylated protein. The lower in vitro biological activity of glycosylated GM-CSF is due to a reduction in receptor binding affininty $[17,18]$.

Here, we describe the design of a basic but robust fedbatch fermentation process for the production of a $\mathrm{Man}_{5} \mathrm{GlcNAc}_{2}$ glycoform of mGM-CSF by a glycoengineered $P$. pastoris strain. This approach allowed for maximal production at high cell densities while maintaining $\mathrm{N}$-glycan homogeneity.

\section{Materials and methods}

\section{Strains and media}

Escherichia coli MC1061 was used as the host strain for plasmid propagation. The bacteria were cultivated in LB medium ( $1 \%$ tryptone, $0.5 \%$ yeast extract, and $0.5 \%$ sodium chloride) containing $100 \mu \mathrm{g} / \mathrm{ml}$ ampicillin.
The P. pastoris GlycoSwitch-Man5 strain modifies its glycoproteins predominantly with $\mathrm{Man}_{5} \mathrm{GlcNAc}_{2} \mathrm{~N}-$ glycans. It only differs from a previously reported GS115-derived strain in the selection marker used to engineer the $\mathrm{N}$-glycosylation pathway, blasticidin instead of zeocine [7].

Small-scale $P$. pastoris cultivation was performed in BMGY (1\% yeast extract, $2 \%$ peptone, $1.34 \%$ yeast nitrogen base, $100 \mathrm{mM}$ potassium phosphate buffer [pH 6.0], $1 \%$ glycerol) and BMMY medium (1\% yeast extract, $2 \%$ peptone, $1.34 \%$ yeast nitrogen base, $100 \mathrm{mM}$ potassium phosphate buffer [pH 6.0], 1\% methanol).

Fermentations were performed in FM22 medium [19], which is deionized water containing (per liter): $42.9 \mathrm{~g}$ $\mathrm{KH}_{2} \mathrm{PO}_{4}, 5.0 \mathrm{~g}\left(\mathrm{NH}_{4}\right)_{2} \mathrm{SO}_{4}, 1.0 \mathrm{~g} \mathrm{CaSO}_{4} .2 \mathrm{H}_{2} \mathrm{O}, 14.3 \mathrm{~g}$ $\mathrm{K}_{2} \mathrm{SO}_{4}, 11.7 \mathrm{~g} \mathrm{MgSO}_{4} .7 \mathrm{H}_{2} \mathrm{O}, 40.0 \mathrm{~g}$ glycerol. Prior to inoculation, the $\mathrm{pH}$ was adjusted to 5.0 with concentrated ammonium hydroxide followed by the addition of $8.7 \mathrm{ml}$ of Pichia Trace Metals (PTM1; containing, per liter, $6.0 \mathrm{~g} \mathrm{CuSO}_{4 \cdot 5} \mathrm{H}_{2} \mathrm{O}, 0.08 \mathrm{~g} \mathrm{NaI}, 3.0 \mathrm{~g} \mathrm{MnSO}_{4} \cdot \mathrm{H}_{2} \mathrm{O}$, $0.2 \mathrm{~g} \mathrm{Na}_{2} \mathrm{MoO}_{4} .2 \mathrm{H}_{2} \mathrm{O}, 0.02 \mathrm{~g} \mathrm{H}_{3} \mathrm{BO}_{3}, 0.5 \mathrm{~g} \mathrm{CoCl}_{2}, 20.0$ $\mathrm{g} \mathrm{ZnCl}_{2}, 65 \mathrm{~g} \mathrm{FeSO}_{4} .7 \mathrm{H}_{2} \mathrm{O}, 0.2 \mathrm{~g}$ biotin, and $5.0 \mathrm{ml}$ $\mathrm{H}_{2} \mathrm{SO}_{4}$ ).

\section{Vector construction and transformation}

The $P$. pastoris expression vector pPIC9mGM-CSF contains the mature mouse GM-CSF coding sequence fused in-frame to the $S$. cerevisiae alfa mating factor signal sequence under transcriptional control of the $A O X 1$ promoter. The mGM-CSF ORF was amplified by PCR using pORF9-mGMCSF (Invivogen) as template and the oligonucleotides 5'-CTAGCTCGAGAAAAGAGAGGCTGAAGCCGCACCCACCCGCTCACCC-3' and 5'-AGTTTAGCGGCCGCTCATTTTTGGCCTGGTTT TTTGC-3' as primers (XhoI and NotI restriction sites are underlined). Subsequently, an XhoI/NotI fragment was cloned into the Xhol/NotI opened pPIC9 expression vector (Invitrogen).

Linearized vectors (SalI) were transformed into P. pastoris GS115 and GlycoSwitch-Man5 as described [20], resulting in GS115mGM-CSF and Man5mGM-CSF, respectively. Genomic integration was confirmed by performing PCR on genomic DNA.

\section{Small scale shake flask expression conditions}

Cells were grown in $10 \mathrm{ml} \mathrm{BMGY}$ medium at $30^{\circ} \mathrm{C}$. After 48 hours of cultivation, the cells were pelleted by centrifugation at $3000 \mathrm{~g}$ for 5 minutes and resuspended in BMMY medium. Induction was maintained for another 48 hours by spiking the cultures twice daily with $100 \mu \mathrm{l}$ of $100 \%$ methanol (1\% final concentration). Subsequently, the cultures were harvested by centrifugation $(3000 \mathrm{~g}$ for 10 minutes) and the supernatants were frozen at $-20^{\circ} \mathrm{C}$ until further use. 


\section{Fermentor setup}

Fermentations were carried out in 5-liter BioFlo III or 3000 bioreactors (New Brunswick Scientific) containing two liters of FM22 medium [19] supplemented with 8.7 ml PTM1 trace salts (added after autoclaving). The temperature was maintained at $30^{\circ} \mathrm{C}$ and the $\mathrm{pH}$ at 5.0 (controlled with concentrated ammonium hydroxide). The dissolved oxygen (DO) was set to $40 \%$ and controlled by an agitation $/ \mathrm{O}_{2}$ cascade. Pure oxygen was supplemented as needed to maintain the DO setpoint. A part of the off-gas was diverted to an MC-168 methanol monitor and controller (PTI Instruments) equipped with a TGS822 methanol sensor (Figaro Engineering), which were used to maintain a constant level of methanol in the broth. A methanol feed pump (Model 101U/R, Watson-Marlow), balance (Model PR1203, Mettler Toledo) and the MC-168 controller were interfaced with the NBS-BioCommand supervisory control and data acquisition software to make a closed-loop feed control system. The amount of methanol delivered was measured using a balance as the difference between the initial mass in the methanol tank and the current mass.

The $P$. pastoris strain Man5mGM-CSF was grown in a 1-liter shake flask with $300 \mathrm{ml}$ BMGY medium for 20$24 \mathrm{~h}$ at $30^{\circ} \mathrm{C}$ and $300 \mathrm{rpm}$ to an optical density (at 600 $\mathrm{nm}$ ) of 4-8. Following microscopic examination for contamination, $100 \mathrm{ml}$ of this pre-culture was used as inoculum.

To increase cell mass and simultaneously prepare the cells for induction, a glycerol fed-batch phase was performed. A 1-hour fed-batch period was used at a feed

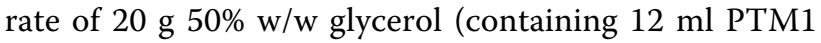
trace salts per liter) per hour per liter of broth. Following the fed-batch phase, a transition phase was applied to shorten the time required for the cells to fully adapt to methanol. The transition phase was initiated by the addition of $1.5 \mathrm{~g} / \mathrm{l}$ methanol. Simultaneously, the glycerol feed rate was ramped down linearly from $20 \mathrm{~g} / \mathrm{l} / \mathrm{h}$ to 0 over a 3 - $h$ period. By the end of the transition phase, the cells were fully adapted to methanol, which was confirmed by a sharp drop in DO [21].

Once the cells were fully adapted to methanol, the methanol fed-batch phase was started. Methanol supplemented with $12 \mathrm{ml}$ of PTM1 per liter was used. Two feeding strategies were applied. The first was a methanol-excess feed strategy in which the methanol concentration was kept constant at $\sim 2 \mathrm{~g} / \mathrm{l}$. This allowed the maximum specific growth rate $\left(\mu_{\max }\right)$ to be determined. The second strategy used methanol-limited feeding to maintain the growth rate below $\mu_{\max }$ at a constant predetermined value. This was achieved by varying the methanol feed rate (F) exponentially, using the following equation [21]:

$$
\mathrm{F}=\mathrm{v}_{\mathrm{MeOH}}\left(\mathrm{X}_{0} \mathrm{~V}_{0}\right) e^{\mu \mathrm{t}}
$$

$\mathrm{X}_{0}$ is the cell density and $\mathrm{V}_{0}$ the broth volume at the start of the feeding profile $(t=0), \mu$ is the desired specific growth rate $\left(\mathrm{h}^{-1}\right)$, and $v_{\mathrm{MeOH}}$ is the specific methanol consumption rate $(\mathrm{g} / \mathrm{g} / \mathrm{h})$. The latter can be calculated once $\mu_{\max }$ and $v_{\mathrm{MeOH}}$, max have been determined empirically under methanol excess conditions. For a desired $\mu$, $v_{\mathrm{MeOH}}$ is estimated by the following equation:

$$
v_{\mathrm{MeOH}}=\mu v_{\mathrm{MeOH}, \max } / \mu_{\max }
$$

Equation (2) is based on the assumption that the yield of biomass to substrate $\mathrm{Y}_{\mathrm{X} / \mathrm{S}}=\mu_{\max } / \nu_{\mathrm{MeOH} \text {,max }}$ and is independent of $\mu$ and that the maintenance coefficient is negligible [21].

\section{Protein purification}

All purification steps were conducted at $4^{\circ} \mathrm{C}$. A GS115 mGM-CSF-secreting clone was grown in BMGYcontaining shake flasks at $30^{\circ} \mathrm{C}$. After 24 hours of cultivation, the cells were harvested by centrifugation and mGM-CSF protein expression was induced by resuspending the cell pellet in BMMY medium containing $2 \%$ methanol. At 24, 36 and 48 hours of induction, $2 \%$ methanol was added to maintain induction. After 60 hours, five liter of cultivation medium was then obtained upon centrifugation at $18,000 \mathrm{~g}$ for 30 minutes. Ammonium sulphate was added to $80 \%$ saturation and the suspension was incubated overnight to precipitate the protein fraction. The protein pellet was isolated by centrifugation at $18,000 \mathrm{~g}$ for 30 minutes and redissolved in $90 \mathrm{ml}$ of $25 \mathrm{mM}$ sodium acetate $\mathrm{pH} 4.5,0.1 \%$ CHAPS. After centrifugation at $40,000 \mathrm{~g}$ for 30 minutes to remove a minor non-soluble fraction, this solution was desalted on a Sephadex G25 column of $475 \mathrm{ml}($ XK26 $\times 90 \mathrm{~cm}$, GE Healthcare) to $25 \mathrm{mM}$ sodium acetate $\mathrm{pH} 4.5,0.1 \%$ CHAPS. The desalted protein fraction was loaded on a $20 \mathrm{ml}$ Source $15 \mathrm{~S}$ column $($ XK16 $\times 10 \mathrm{~cm}$, GE Healthcare) to remove contaminants and potential endotoxins. After equilibration, mGM-CSF was eluted by a linear gradient over 20 column volumes of $\mathrm{NaCl}$ from 0 to 1 $\mathrm{M}$ in $25 \mathrm{mM}$ sodium acetate $\mathrm{pH} 4.5,0.1 \%$ CHAPS. The obtained fractions were analyzed by SDS-PAGE. The major mGM-CSF-containing fractions were pooled and loaded onto a HiLoad 26/60 Superdex 75 prep grade size exclusion column (GE Healthcare) with PBS as the elution buffer. Following concentration of the product peak by ultrafiltration (Vivaspin 20, 3000 MWCO; Sartorius Stedim Biotech), the mGM-CSF concentration was determined using the BCA assay (Pierce) and endotoxin levels were determined with the ToxinSensor Chromogenic LAL Endotoxin Assay Kit (GenScript 
USA). The process generated $92 \mathrm{mg} \mathrm{mGM}-\mathrm{CSF}$ from 5 liter of supernatant $(18 \mathrm{mg} / \mathrm{l})$ with a purity $>95 \%$ based on SDS-PAGE and an endotoxin level of $0.15 \mathrm{EU} / \mathrm{mg}$.

mGM-CSF activity in murine monocyte differentiation into dendritic cells

Bone marrow (BM) cells ( $\mathrm{C} 57 \mathrm{Bl} / 6$ mice) were cultured for 8 days in dendritic cell (DC) culture medium: RPMI 1640 containing GlutaMAX-I, supplemented with 5\% (vol/vol) FCS, $50 \mu \mathrm{M} \beta$-mercaptoethanol and $20 \mathrm{ng} / \mathrm{ml}$ mGM-CSF, the latter either produced in E. coli (Peprotech) or in-house in $P$. pastoris. Following differentiation, bone marrow-derived DCs (BM-DCs) were infected for $24 \mathrm{~h}$ with Mycobacterium bovis BCG 1721, a derivative of $M$. bovis BCG Pasteur, carrying a nonrestrictive rpsL alteration. Following infection, the BMDCs were collected by centrifuging (10 min at $150 \mathrm{~g}$ and $4^{\circ} \mathrm{C}$ ). After washing in PBS, the cells (both infected and non-infected) were stained for different cell surface markers, i.e. CD40-biotin (Pharmingen), CD86-biotin (Pharmingen), followed by streptavidin-PE, CD80-PE (Pharmingen), CD273-PE (Pharmingen), CD274-PE (Pharmingen), CD1d-PE (eBioscience). The expression of these surface markers was checked on the CD11c positive population (a marker for DCs) with CD11c-PECy5 (eBioscience), which was almost $100 \%$ in both preparations. Measurements were performed on a FACSCalibur flow cytometer (BD Biosciences) equipped with CellQuest software.

\section{Analytical techniques}

Secreted proteins were TCA precipitated by adding $10 \%$ $\mathrm{v} / \mathrm{v} 10 \mathrm{mg} / \mathrm{ml}$ deoxycholate and $10 \%$ trichloro acetic acid. After centrifugation $\left(20 \mathrm{~min}\right.$ at $>10.000 \mathrm{~g}$ and $4^{\circ} \mathrm{C}$ ) the protein pellet was dissolved in Laemmli loading buffer supplemented with $1 \mathrm{M}$ unbuffered Tris to neutralize the solution and boiled for 10 minutes. Samples were analyzed by SDS-PAGE using 15\% gels casted in-house according to [22]. Proteins were visualized by staining with Coomassie Brilliant Blue (Sigma) or blotted onto nitrocellulose membranes (Hybond-C extra, $45 \mu \mathrm{m}$, Amersham Life Science) using the Mini Trans-Blot Cells from Bio-Rad (Hercules, CA, USA). Western blot analysis [23] was performed using a rat anti-mGM-CSF monoclonal antibody (Imgenex) at a concentration of $1 \mu \mathrm{g} / \mathrm{ml}$ ( 2 hours) and a horseradish peroxidase-conjugated goat anti-rat IgG (Sigma) as the secondary antibody (2 hours). Samples were deglycosylated by treatment with PNGase F (New England Biolabs). Nlinked oligosaccharides were analyzed by fluorophoreassisted carbohydrate electrophoresis (FACE), with an ABI 3130 capillary DNA sequencer as described previously [24].
Cell density was expressed as wet cell weight (WCW). This was done by sampling duplicate $10 \mathrm{ml}$ aliquots of the fermentation broth into preweighed $15 \mathrm{ml}$ conical tubes. The samples were centrifuged at $10.000 \mathrm{~g}$, the supernatants were discarded, and the pellets were weighed. One gram WCW/l is equivalent to $\sim 0.27 \mathrm{~g}$ dry cells/l $1 \mathrm{OD}_{600}[25]$.

Murine GM-CSF expression levels were quantified by ELISA (eBioscience). After correction for cell density, yields were expressed as milligram per liter fermentation broth.

\section{Results and Discussion}

\section{Expression vector construction and GS115mGM-CSF strain} generation

The sequence encoding the mature mGM-CSF protein was PCR amplified and cloned in the $P$. pastoris pPIC9 expression vector, in-frame with the $S$. cerevisiae $\alpha$ mating factor prepropeptide coding sequence and under transcriptional control of the $P$. pastoris $A O X 1$ promoter. The resulting vector was termed pPIC9mGM-CSF (Figure 1A). It has been reported that incorporation of Glu-Ala repeats immediately following the Kex $2 p$ recognition site can significantly increase Kex $2 p$ processing efficiency and final secreted product yield [26]. Therefore, to enhance cleavage of the secretion signal, we inserted two Glu-Ala repeats after the Kex $2 p$ recognition site (Figure $1 B$ ).

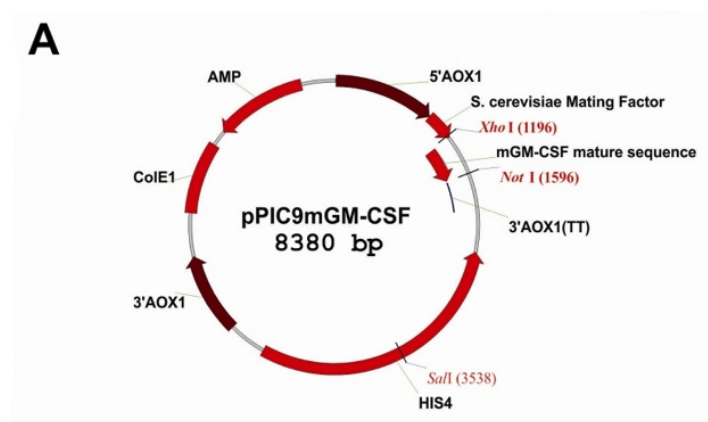

B

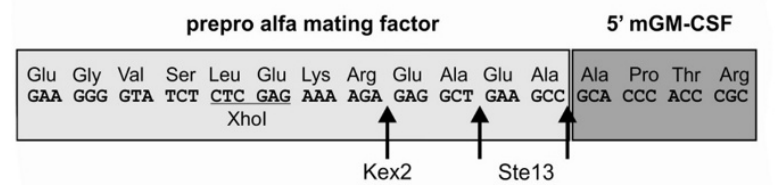

Figure 1 (A) Schematic representation of the pPIC9mGM-CSF expression vector and (B) Secretion signal processing. The $S$. cerevisiae $\alpha$-factor secretion signal is removed by the consecutive action of two enzymes: Kex $2 p$ cleaves between the arginine and the glutamic acid residue in the sequence EKREAEA; Ste13p removes both EA repeats. 
The SalI-linearized pPIC9mGM-CSF vector was subsequently transformed to the wild type $P$. pastoris strain GS115. Twelve individual clones were analyzed by SDSPAGE for mGM-CSF secretion in the culture supernatant (data not shown). Eleven clones effectively produced mGM-CSF and the one with the highest expression level was withheld for further analysis. This strain was named GS115mGM-CSF. SDS-PAGE analysis showed that mGM-CSF was produced as three molecular species ranging in molecular weight from $\sim 14$ to $\sim 18$ $\mathrm{kDa}$ (Figure 2). After de-N-glycosylation with PNGase F, only one $\sim 14 \mathrm{kDa}$ band remained. Since mGM-CSF has two potential $\mathrm{N}$-glycosylation sites, this indicates that the upper and middle bands correspond to mGM-CSF carrying two and one $\mathrm{N}$-glycans, respectively, while the minor lower band is non-N-glycosylated mGM-CSF (Figure 2). Although we did not perform N-terminal sequencing, the fact that de-N-glycosylated mGM-CSF appeared on SDS-PAGE (Figure 2) and Western blot (data not shown) as a protein of $\sim 14 \mathrm{kDa}$ (which corresponds very well with a theoretical molecular weight of $14.1 \mathrm{kDa}$ ) indicates that Kex2p processing was very

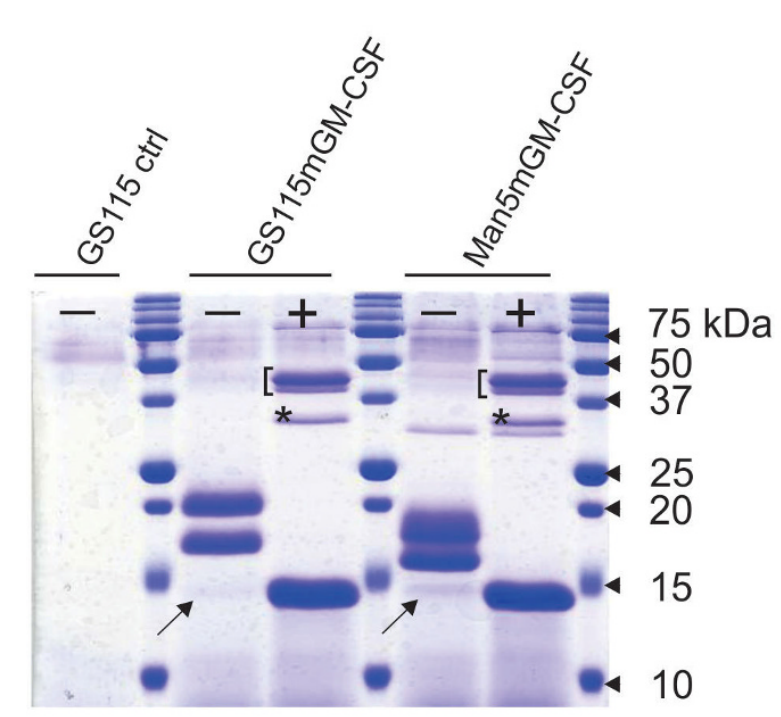

Figure 2 SDS-PAGE analysis of GS115, GS115mGM-CSF and Man5mGM-CSF culture supernatant untreated (-) or treated with PNGase $\mathbf{F}(+)$. Mouse GM-CSF appears as three molecular species ranging in molecular mass from approximately 14 to 18 kDa. Treatment with PNGase F showed that the upper two bands correspond to mGM-CSF carrying two and one N-glycans, while the minor lower band (indicated with an arrow) is non-N-glycosylated mGM-CSF. The extra band indicated with an asterisk in both " + " lanes is PNGase F. The two bands marked with a bracket in the " + " lanes are highly $\mathrm{N}$-glycosylated endogenous $P$. pastoris glycoproteins that, due to their extensive and heterogeneous modification with carbohydrates, do not present as one single band on SDS-PAGE. Upon de-N-glycosylation, however, this heterogeneity is eliminated, resulting in two clearly defined bands. efficient. After all, non-cleavage of the prepropeptide by Kex2p would have increased the molecular weight by at least $9 \mathrm{kDa}$ (not taking into account the contribution of oligosaccharides attached to the three potential $\mathrm{N}$ glycosylation sites of the prepropeptide). A potential downside of this approach, however, is subsequent incomplete removal of both Glu-Ala repeats by Ste13p, resulting in a final product with two or four additional $\mathrm{N}$-terminal amino acids. We did not determine the extent to which this happened, though, since we were primarily concerned about introducing additional N-glycosylation sites through inefficient Kex2p processing.

\section{P. pastoris-produced mGM-CSF is biologically active}

To ascertain that $P$. pastoris is a suitable host organism for the production of biologically active mGM-CSF, the latter was purified from the culture supernatants of shake flask cultures of GS115mGM-CSF to a final yield of $\sim 18 \mathrm{mg} / \mathrm{l}$ and an endotoxin content of $0.15 \mathrm{EU} / \mathrm{mg}$. $P$. pastoris-produced mGM-CSF was then used head-tohead against commercially available $E$. coli-produced mGM-CSF (Peprotech) to differentiate murine bone marrow-derived monocytes into dendritic cells (BMDC). Similar expression of 6 differentiation/activationassociated cell surface markers on BM-DCs that were either differentiated with Pichia-derived or E. coliderived mGM-CSF demonstrated that both forms are equally potent. Additionally, both sets of BM-DCs responded similarly to an $M$. bovis BCG infection, confirming that differentiation with $P$. pastoris- or E. coliderived mGM-CSF does not induce phenotypic differences during the differentiation process (Figure 3; results shown are representative for three independent experiments). This demonstrates that mGM-CSF produced in $P$. pastoris is as biologically active as the commercial E. coli preparation. As a testament to the quality of the $P$. pastoris-derived mGM-CSF, immunologists in our department have switched to utilizing $P$. pastoris-derived mGM-CSF for murine dendritic cell differentiation.

\section{Man5mGM-CSF strain selection}

GlycoSwitch-Man5, a glycoengineered GS115-derived $P$. pastoris strain that predominantly modifies its glycoproteins with $\mathrm{Man}_{5} \mathrm{GlcNAc}_{2} \mathrm{~N}$-glycans, was subsequently used as the host strain. Upon transformation of the expression vector pPIC9mGM-CSF to GlycoSwitchMan5, 18 individual clones were evaluated for mGM-CSF expression by SDS-PAGE of the culture supernatant; 13 (68\%) expressed mGM-CSF (data not shown). These clones were designated Man5mGM-CSF. As did the wild type strain, the GlycoSwitch-Man5 strain produced mGM-CSF as three distinct glycoforms, i.e., modified with two, one or no N-glycans (Figure 2). 


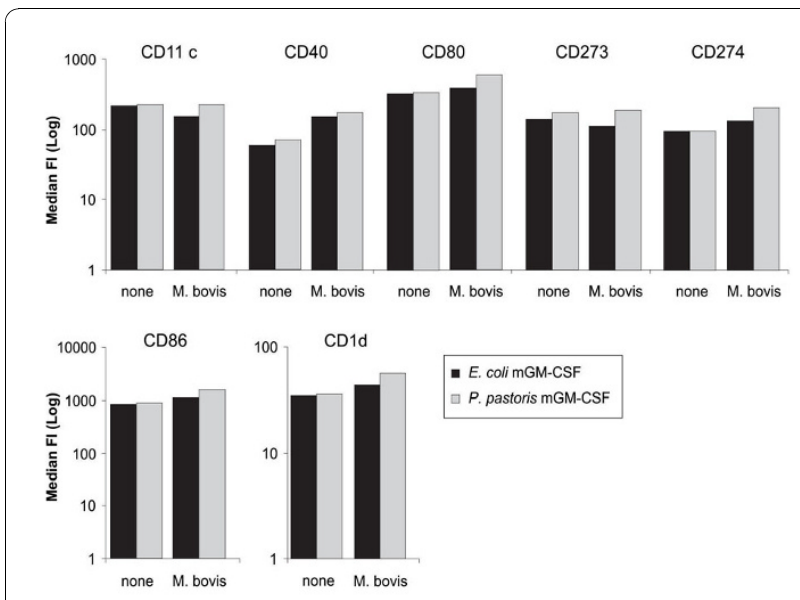

Figure $3 P$. pastoris-produced $\mathrm{mGM}$-CSF is biologically active Mouse bone marrow cells were differentiated into DCs using either E. coli- (black bars) or P. pastoris-produced (grey bars) mGM-CSF. Six surface maturation markers were measured by flow cytometry on non-infected ('none') or M. bovis BCG-infected BM-DCs ('M. bovis'), which were also CD11c+. Both mGM-CSF preparations were equally potent in differentiating bone marrow cells into BM-DCs (similar expression of cell surface markers). The latter also responded similarly to a stimulus, i.e., infection with M. bovis BCG, regardless of the source of mGM-CSF used for differentiation. The percentage of obtained CD11c+ cells was also very similar for both mGM-CSF sources (almost 100\%; data not shown). This demonstrates that, based on cell surface marker expression and reaction to $M$. bovis BCG infection, both sources of mGM-CSF produced phenotypically indistinguishable BM-DCs.

As a result of the engineered N-glycosylation pathway, however, both $\mathrm{N}$-glycosylated bands possessed a discernible higher electrophoretic mobility on SDS-PAGE compared to GS115-produced mGM-CSF. De-Nglycosylation with PNGase F completely eliminated this difference in molecular weight, indicating that it was entirely attributable to the presence of different size $\mathrm{N}$ glycans (Figure 2).

Next, for each Man5mGM-CSF clone, the N-glycans on secreted glycoproteins were analyzed by DSA-FACE. Based on mGM-CSF expression levels and N-glycan homogeneity, one clone was withheld for further analysis. Figure 4 shows DSA-FACE profiles for the selected Man5mGM-CSF clone. The predominant (>90\%) Nlinked glycan was $\mathrm{Man}_{5} \mathrm{GlcNAc}_{2}$ (Figure 4, panel 3). For comparison, glycoproteins secreted by wild type $P$. pastoris (GS115mGM-CSF) were mostly modified with a heterogeneous array of high-mannose-type $\mathrm{N}$-glycans (Figure 4, panel 2). A minor fraction $(<10 \%)$ of the total $\mathrm{N}$-glycan pool secreted by Man5mGM-CSF was composed of higher molecular weight structures (marked with an asterisk in Figure 4, panel 3). For the majority of these peaks, however, in vitro $\alpha-1,2$-mannosidase digestion did not cause a shift in mobility, indicating that these peaks were not the result of incomplete

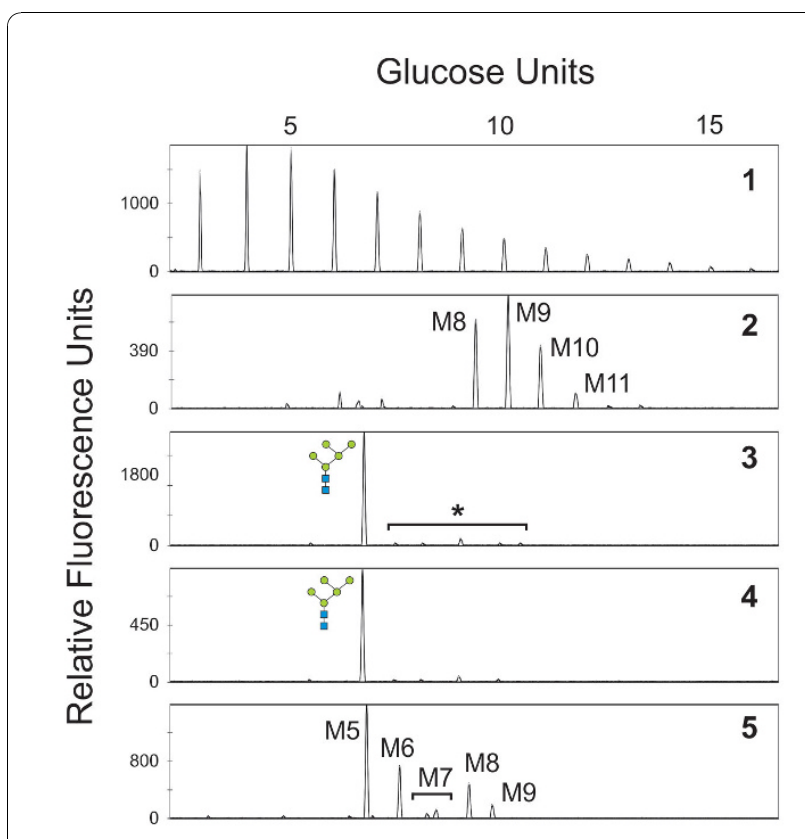

Figure 4 DSA-FACE analysis of the total N-glycan pool from Man5mGM-CSF strain. Panel 1 shows the results for a maltodextrose reference. Panels 2 through 5 show the results for $\mathrm{N}$ glycans, as follows: panel 2: GS115mGM-CSF (the main peak is Man $_{9} G_{L}{ }_{1} N A C_{2}$ [M9]); panel 3, Man5mGM-CSF (the predominant peak is $\mathrm{Man}_{5} \mathrm{GlCNAC}_{2}$; a minor fraction of higher molecular weight structures is marked with an asterisk); panel 4 , same as panel 3 but the $\mathrm{N}$-glycans were treated with $\alpha-1,2$-mannosidase; panel 5, reference $\mathrm{N}$-glycans from bovine RNase B ( $\mathrm{Man}_{5-9} \mathrm{GlcNAc}_{2}$ [M5-M9]).

trimming by the introduced $T$. reesei $\alpha-1,2$-mannosidase (in Figure 4, compare panels 3 and 4).

\section{Maximum specific growth rate $\left(\mu_{\max }\right)$ under methanol excess conditions}

To determine $\mu_{\max }$ of Man5mGM-CSF when methanol is in excess, bioreactor fermentations were performed with a constant methanol concentration (S) of $\sim 2 \mathrm{~g} / \mathrm{l}$. Only minor fluctuations in methanol concentration were observed throughout the fermentations. $\mu_{\max }$ and $v_{\mathrm{MeOH}, \max }$ were $0.0624 \mathrm{~h}^{-1}$ and $0.0743 \mathrm{~g} / \mathrm{g} \mathrm{WCW} / \mathrm{h}$, respectively. This corresponds to a $\mathrm{Y}_{\mathrm{X} / \mathrm{S}}$ (yield of biomass to substrate) of $0.8398 \mathrm{~g} / \mathrm{g}$. For comparison, the 'empty' GlycoSwitch-Man5 strain, i.e., GlycoSwitchMan5 transformed with pPIC9, had a $\mu_{\max }$ and $v_{\mathrm{MeOH}}$, $\max$ of $0.0816 \mathrm{~h}^{-1}$ and $0.052 \mathrm{~g} / \mathrm{g} \mathrm{WCW} / \mathrm{h}$, respectively, corresponding to a $Y_{X / S}$ value of $1.569 \mathrm{~g} / \mathrm{g}$. These data illustrate the burden that mGM-CSF expression places on the cells: $\mu_{\max }$ of Man5mGM-CSF is about $76 \%$ of $\mu_{\max }$ of Man5. Moreover, under excess methanol conditions, Man5mGM-CSF is about 50\% less efficient in converting methanol to biomass than GlycoSwitchMan5. 


\section{Methanol-limited cultures}

By substitution of $\mu_{\max }$ and $v_{\mathrm{MeOH}, \max }$ into equations (1) and (2), the methanol feed rate, F, needed to achieve a desired $\mu$ could be estimated by the following equation:

$$
\mathrm{F}=1.1907 \mu\left(\mathrm{X}_{0} \mathrm{~V}_{0}\right) \mathrm{e}^{\mu \mathrm{t}}
$$

The desired values for $\mu$ were set to $0.0156 \mathrm{~h}^{-1}(25 \%$ $\left.\mu_{\max }\right), 0.0312 \mathrm{~h}^{-1}\left(50 \% \mu_{\max }\right)$ and $0.0468 \mathrm{~h}^{-1}\left(75 \% \mu_{\max }\right)$. $\mathrm{X}_{0}$ and $\mathrm{V}_{0}$ were determined just prior to the start of the methanol feed profile. The actual $\mu$ values were $0.015 \mathrm{~h}^{-1}$, $0.0332 \mathrm{~h}^{-1}$, and $0.0459 \mathrm{~h}^{-1}$, which correlated very well to the desired values. Figure 5 shows the evolution of several key parameters over time for the fermentation of Man5mGM-CSF at $0.015 \mathrm{~h}^{-1}\left(\sim 25 \%\right.$ of $\left.\mu_{\max }\right)$.

\section{mGM-CSF yield}

Protein production kinetics of the four fed-batch fermentation types are shown in Figure 6. Murine GMCSF yield per unit volume of fermentation broth
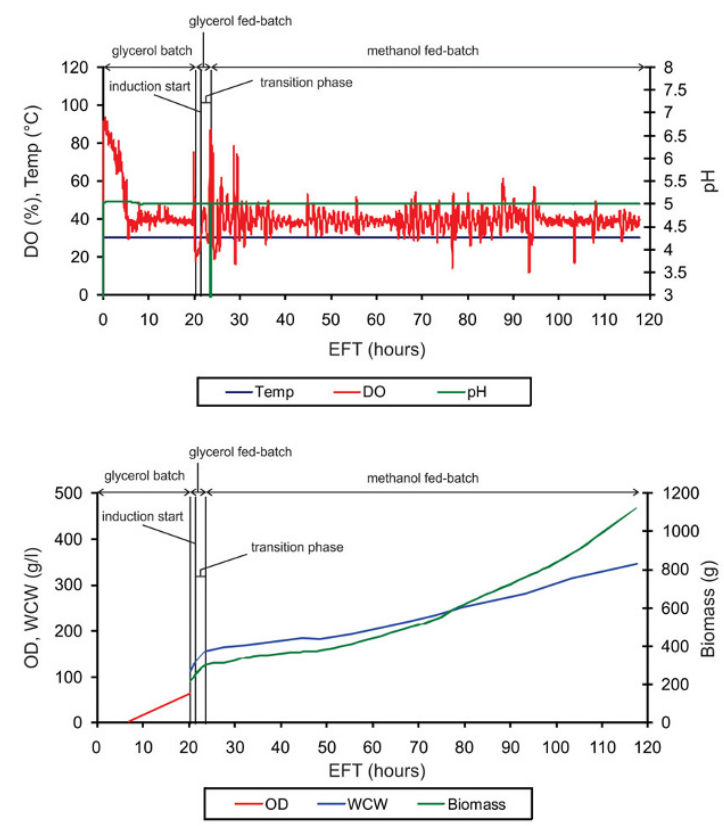

Figure 5 Fermentation of Man5mGM-CSF at $0.015 \mathrm{~h}^{-1}(\sim 25 \%$ of $\left.\boldsymbol{\mu}_{\max }\right)$. Plotted parameters show dissolved oxygen (DO), $\mathrm{pH}$, temperature, $\mathrm{OD}_{600}, \mathrm{WCW}$ and biomass during 70 hours of fermentation. The initial batch was grown in FM22 media containing $40 \mathrm{~g} / \mathrm{l}$ glycerol. Following an increase in DO due to carbon source limitation at around $20 \mathrm{~h}$ EFT, the glycerol fed-batch process was initiated. Glycerol was added at $20 \mathrm{~g} / / / \mathrm{h}$ for 1 hour. The transition phase was initiated by the addition of $1.5 \mathrm{~g} / \mathrm{l}$ methanol. Simultaneously, the glycerol feed rate was ramped down linearly from $20 \mathrm{~g} / \mathrm{l} / \mathrm{h}$ to 0 over a 3-h period. By the end of the transition phase, the cells were fully adapted to methanol, which was confirmed by a sharp drop in DO. At this point, methanol feeding was initiated. DO was maintained at $40 \%$.

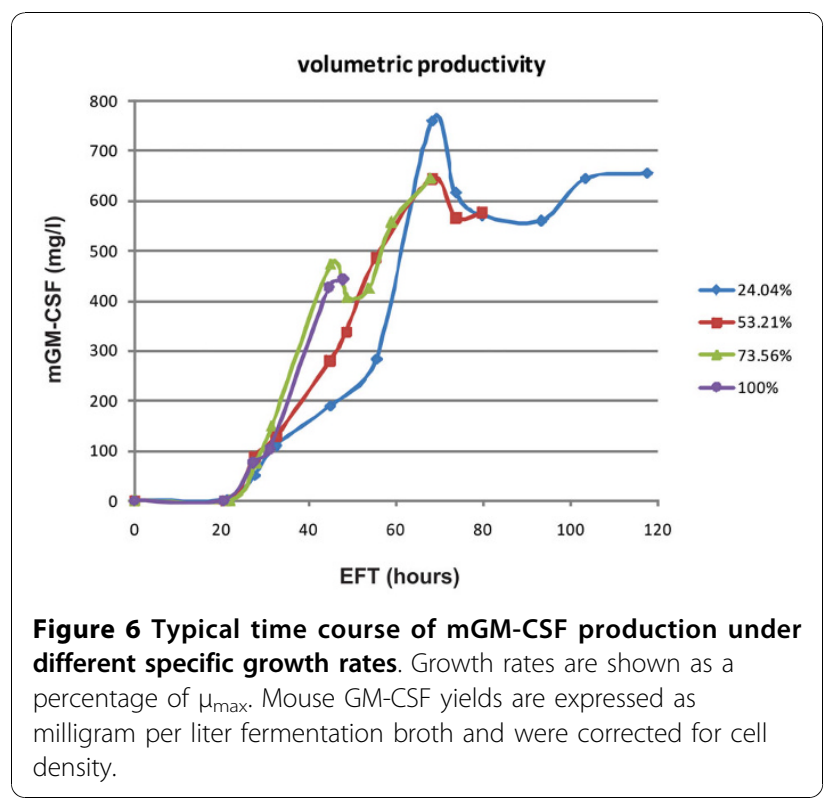

(i.e., after correction for cell density) was maximum by growing the cells at $\mu=0.015 \mathrm{~h}^{-1}\left(24.04 \% \mu_{\max }\right)$ during the induction phase. In this way, a volumetric yield of $760 \mathrm{mg} / \mathrm{l}$ could be achieved after $\sim 68 \mathrm{~h}$ of fermentation. Although volumetric yields decreased slightly after this time point, total mGM-CSF levels continued to increase during the entire course of the fermentation. Higher growth rates resulted in decreased yields (Table 1). Both growth at $\mu=0.0332 \mathrm{~h}^{-1}\left(53.21 \% \mu_{\max }\right)$ and $\mu=0.0459$ $\mathrm{h}^{-1}\left(73.56 \% \mu_{\max }\right)$ decreased yields by about $15.3 \%$. Allowing the cells to achieve their maximum growth rate under methanol conditions $\left(\mu_{\max }=0.0624 \mathrm{~h}^{-1}\right)$ further decreased mGM-CSF yields by as much as $42 \%$ (442 $\mathrm{mg} / \mathrm{l})$. Hence, limiting the growth rate during the induction phase to $\sim 25 \%$ of $\mu_{\max }$ resulted in maximum mGM-CSF yield. During the entire course of fermentation, total recombinant mGM-CSF levels kept increasing regardless of the specific growth rate (data not shown), indicating that proteolytic degradation was not a significant problem. This is in contrast to many other recombinant proteins produced in P. pastoris that get increasingly degraded during the fermentation $[27,28]$.

Table 1 Effect of various specific growth rates on mGMCSF production

\begin{tabular}{cccc}
\hline $\begin{array}{c}\text { Specific growth } \\
\text { rate, } \boldsymbol{\mu}\left(\mathbf{h}^{-\mathbf{1}}\right)\end{array}$ & $\begin{array}{c}\text { Elapsed fermentation } \\
\text { time }(\mathbf{h})\end{array}$ & $\begin{array}{c}\text { Wet cell } \\
\text { density } \\
(\mathbf{g} / \mathbf{l})\end{array}$ & $\begin{array}{c}\text { Max mGM-CSF } \\
\text { yield }^{\mathbf{a}}(\mathbf{m g} / \mathbf{l})\end{array}$ \\
\hline 0.0624 & 47.76 & 368.3 & 442.7 \\
0.0459 & 67.99 & 448 & 644.0 \\
0.0332 & 68.25 & 370.25 & 644.4 \\
0.015 & 68.25 & 221.4 & 760.4 \\
\hline
\end{tabular}

${ }^{a}$ Refers to mGM-CSF yield per unit volume of the fermentation broth. 


\section{$\mathrm{N}$-glycan analysis}

Fermentation supernatant samples were analyzed by DSA-FACE (Figure 7). The predominant peak during the entire course of all fermentations was $\mathrm{Man}_{5-}$ $\mathrm{GlcNAc}_{2}$. Even after $>100$ hours of fermentation, the level of N-glycan homogeneity was comparable to the level obtained in small scale cultures [2]. Since all fermentations were performed under non-selective conditions, this illustrates the stability of the Man5mGM-CSF strain after multiple generations.

Regardless of the specific growth rate, DSA-FACE analysis revealed the presence of low-abundance peaks. Several of these derive from the cultivation medium (not shown), but there is a small fraction $(<10 \%)$ of larger $\mathrm{N}$ glycan species corresponding to $\mathrm{Man}_{6-10} \mathrm{GlcNAc}_{2}$ structures. These oligosaccharides are believed to be the result of 1) incomplete processing by the introduced $\alpha-1,2$ mannosidase-HDEL, 2) interfering endogenous mannosyltransferases, or 3) a combination of those two. Importantly though, growth under fermentation conditions did not decrease the conversion efficiency of $P$. pastoris hypermannosyl-type $\mathrm{N}$-glycans to $\mathrm{Man}_{5} \mathrm{GlcNAc}_{2}$ structures as compared to small scale cultivation experiments, again illustrating the robustness of this strain.

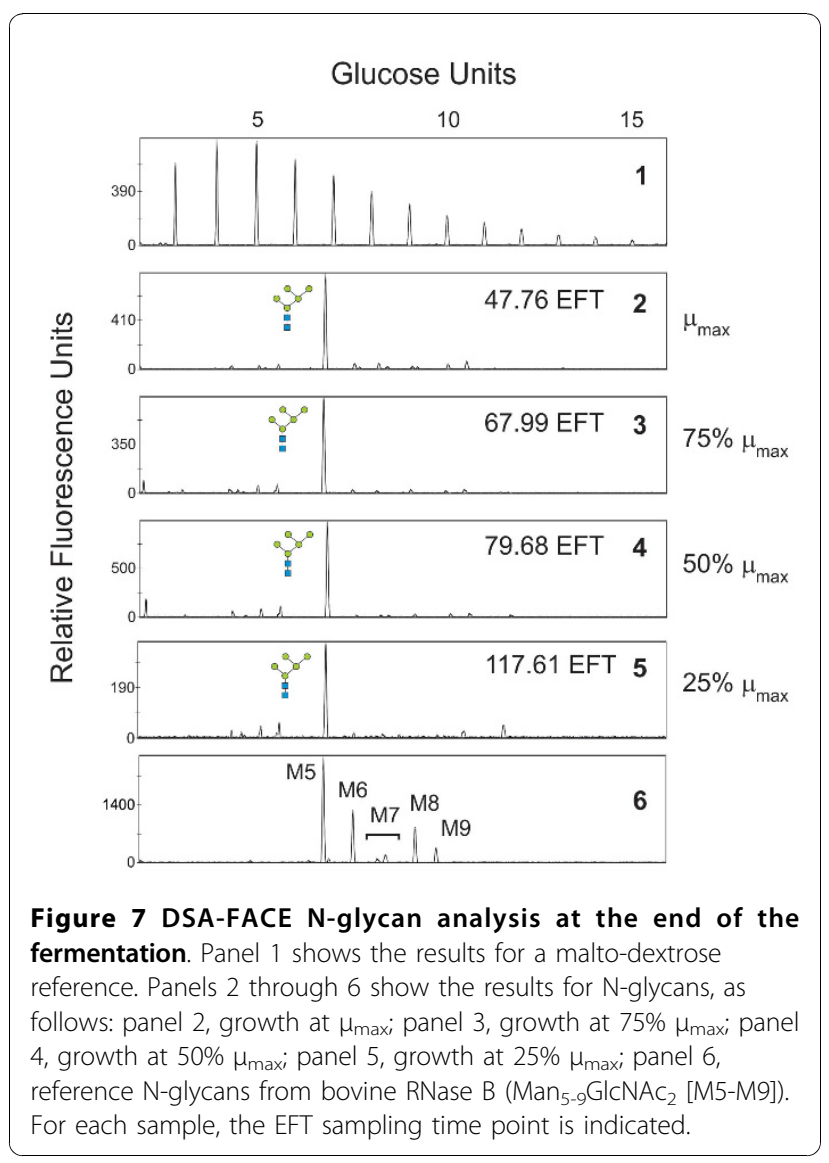

\section{Conclusions}

In this paper, we describe a basic but robust fed-batch fermentation protocol for the secreted production of murine GM-CSF in a glycoengineered $P$. pastoris strain that predominantly modifies its glycoproteins with $\mathrm{Man}_{5} \mathrm{GlcNAc}_{2} \mathrm{~N}$-glycans. We have shown that growth rate does not significantly affect $\mathrm{N}$-glycan homogeneity: regardless of the specific growth rate the predominant peak during the entire course of all fermentations was $\mathrm{Man}_{5} \mathrm{GlcNAc}_{2}$. There was, however, a clear relationship between product yield and specific growth rate. Cultivation of the cells at $\sim 25 \%$ of their maximal growth rate $\left(\mu=0.015 \mathrm{~h}^{-1}\right)$ resulted in a volumetric yield of $\sim 760 \mathrm{mg}$ mGM-CSF per liter fermentation broth after $\sim 68 \mathrm{~h}$ of fermentation. Higher specific growth rates during the induction phase resulted in decreased mGM-CSF yields.

To date, only one similar study has been published. In this paper, researchers at GlycoFi Inc. (a wholly-owned subsidiary of Merck \& Co Inc.) describe a strain capable of producing $>1 \mathrm{~g} / \mathrm{l}$ of human IgG1 with $>90 \%$ homogeneous $\mathrm{Man}_{5} \mathrm{GlcNAc}_{2} \mathrm{~N}$-glycans across a range of fermentation conditions [29]. Unfortunately, the report did not include $\mathrm{N}$-glycan analysis data, which precludes a more direct comparison with our data.

However, it is clear from both reports that conversion of the P. pastoris N-glycosylation pathway to the $\mathrm{Man}_{5} \mathrm{GlcNAc}_{2}$ structure does not affect the yeast's physiology much and that such engineered strains are fully capable of producing diverse mammalian glycoproteins at high levels, with the desired homogenous N-glycosylation. As the $\mathrm{Man}_{5} \mathrm{GlcNAc}_{2}$ structure is the starting point for buildup of mammalian complex-type N-glycans, future studies will address the behaviour of more extensively engineered strains in high cell density cultivation.

\section{List of Abbreviations}

EFT: elapsed fermentation time (h); F: methanol feed rate (g/h); S: methanol concentration (g/L); T: Culture time (h); V: broth volume (L); WCW: wet cell weight; $X$ : cell density (g WCW/L); $Y_{X / s}$ : Yield of biomass to substrate $(g / g) ; \mu$ : Specific growth rate under methanol conditions; $\mu_{\max }$ : maximum specific growth rate under methanol conditions; $v_{\text {max }}$ : maximum specific methanol consumption rate $(\mathrm{g} / \mathrm{g} / \mathrm{h})$

\section{Declaration of competing interests}

The authors MI, NF, JH, AVH and MMM declare that they have no competing interests. PPJ, RC and NC are either inventors or share otherwise in proceeds of licensing of patents and patent applications covering parts of the described GlycoSwitch technology.

\section{Acknowledgements}

We are grateful to Michelle Mathiesen, Paul Bates, and Mark Gouthro for assistance in performing the fermentations. Research was supported by a doctoral grant from the Flanders Agency for Innovation through Science and Technology (IWT) to P.P.J. and a Marie Curie Excellence Grant (MEXT- 
014292) to N.C. Nele Festjens is a postdoctoral fellow of FWO (Fonds Wetenschappelijk Onderzoek - Vlaanderen)

\section{Author details}

'Unit for Molecular Glycobiology, Department for Molecular Biomedical Research, VIB, Ghent, Belgium. ${ }^{2}$ Department of Biomedical Molecular Biology, Ghent University, Ghent, Belgium. ${ }^{3}$ Current Address: Department of Dermatology, Brigham \& Women's Hospital and Harvard Medical School, Boston, MA, USA. ${ }^{4}$ Biological Process Development Facility, Department of Chemical and Biomolecular Engineering, University of Nebraska-Lincoln, Lincoln, NE, USA. ${ }^{5}$ Protein Service Facility, Department for Molecular Biomedical Research, VIB, Ghent, Belgium. 'Laboratory for Protein Biochemistry and Biomolecular Engineering, Department of Biochemistry, Physiology and Microbiology, Ghent University, Ghent, Belgium. ${ }^{7}$ Current Address: Department of Food Engineering, Akdeniz, University, Antalya, Turkey.

\section{Authors' contributions}

PPJ constructed the mGM-CSF expression vector, generated and analyzed the $P$. pastoris strains, performed the fermentations, interpreted the glycan analysis data and drafted the manuscript. $\mathrm{Ml}$ assisted in designing the fermentation strategy. NF performed the monocyte differentiation assay and edited the manuscript. JH purified the Pichia-produced mGM-CSF and edited the manuscript. AVH was responsible for $\mathrm{N}$-glycan analysis. MMM supervised the fermentations and edited the manuscript. RC conceived and initiated the study. NC supervised experiments and reviewed the final manuscript. All authors read and approved the final manuscript.

\section{Received: 9 August 2010 Accepted: 23 November 2010}

Published: 23 November 2010

\section{References}

1. Walsh G: Biopharmaceutical benchmarks 2006. Nat Biotechnol 2006, 24:769-776.

2. Jacobs PP, Geysens S, Vervecken W, Contreras R, Callewaert N: Engineering complex-type N-glycosylation in Pichia pastoris using GlycoSwitch technology. Nat Protoc 2009, 4:58-70.

3. Hamilton SR, Davidson RC, Sethuraman N, Nett JH, Jiang Y, Rios S, Bobrowicz P, Stadheim TA, Li H, Choi BK, et al: Humanization of yeast to produce complex terminally sialylated glycoproteins. Science 2006, 313:1441-1443

4. Jacobs PP, Callewaert N: N-glycosylation engineering of biopharmaceutical expression systems. Curr Mol Med 2009, 9:774-800.

5. Li H, Sethuraman N, Stadheim TA, Zha D, Prinz B, Ballew N, Bobrowicz P, Choi BK, Cook WJ, Cukan M, et al: Optimization of humanized IgGs in glycoengineered Pichia pastoris. Nat Biotechnol 2006, 24:210-215.

6. Callewaert N, Laroy W, Cadirgi H, Geysens S, Saelens X, Min Jou W, Contreras R: Use of HDEL-tagged Trichoderma reesei mannosyl oligosaccharide 1,2-alpha-D-mannosidase for N-glycan engineering in Pichia pastoris. FEBS Lett 2001, 503:173-178

7. Vervecken W, Kaigorodov V, Callewaert N, Geysens S, De Vusser K, Contreras R: In vivo synthesis of mammalian-like, hybrid-type $\mathrm{N}$-glycans in Pichia pastoris. Appl Environ Microbiol 2004, 70:2639-2646.

8. Alexander WS: Cytokines in hematopoiesis. Int Rev Immunol 1998, 16:651-682.

9. Gasson JC: Molecular physiology of granulocyte-macrophage colonystimulating factor. Blood 1991, 77:1131-1145.

10. Shannon MF, Coles LS, Vadas MA, Cockerill PN: Signals for activation of the GM-CSF promoter and enhancer in T cells. Crit Rev Immunol 1997 17:301-323.

11. Barreda DR, Hanington PC, Belosevic M: Regulation of myeloid development and function by colony stimulating factors. Dev Comp Immunol 2004, 28:509-554.

12. Armitage JO: Emerging applications of recombinant human granulocytemacrophage colony-stimulating factor. Blood 1998, 92:4491-4508.

13. Kovacic JC, Muller DW, Graham RM: Actions and therapeutic potential of G-CSF and GM-CSF in cardiovascular disease. J Mol Cell Cardiol 2007 42:19-33.

14. Dorr RT: Clinical properties of yeast-derived versus Escherichia coliderived granulocyte-macrophage colony-stimulating factor. Clin Ther 1993, 15:19-29, discussion 18
15. Nicola NA: GM-CSF. In Cytokine Reference. Volume Volume I: Ligands. Edited by: Oppenheim JJ, Feldman M. London: Academic Press; 2000:899-910.

16. Ernst JF, Mermod JJ, Richman LH: Site-specific O-glycosylation of human granulocyte/macrophage colony-stimulating factor secreted by yeast and animal cells. Eur J Biochem 1992, 203:663-667.

17. Moonen P, Mermod JJ, Ernst JF, Hirschi M, DeLamarter JF: Increased biological activity of deglycosylated recombinant human granulocyte/ macrophage colony-stimulating factor produced by yeast or animal cells. Proc Natl Acad Sci USA 1987, 84:4428-4431.

18. Cebon J, Nicola N, Ward M, Gardner I, Dempsey P, Layton J, Duhrsen U, Burgess AW, Nice E, Morstyn G: Granulocyte-macrophage colony stimulating factor from human lymphocytes. The effect of glycosylation on receptor binding and biological activity. J Biol Chem 1990, 265:4483-4491.

19. Stratton J, Chiruvolu V, Meagher M: High cell-density fermentation. Methods Mol Biol 1998, 103:107-120.

20. Cregg JM, Russel KA: Transformation. In Pichia protocols. Volume 103. Edited by: Higgins DR, Cregg JM. Totowa, NJ: Humana Press; 1998:27-39, [Walker JM (Series Editor): Methods in Molecular Biology].

21. Zhang W, Bevins MA, Plantz BA, Smith LA, Meagher MM: Modeling Pichia pastoris growth on methanol and optimizing the production of a recombinant protein, the heavy-chain fragment $C$ of botulinum neurotoxin, serotype A. Biotechnol Bioeng 2000, 70:1-8.

22. Gallagher SR: One-dimensional SDS gel electrophoresis of proteins. Curr Protoc Mol Biol 2006, Chapter 10, Unit $1012 \mathrm{~A}$.

23. Gallagher S, Winston SE, Fuller SA, Hurrell JG: Immunoblotting and immunodetection. Curr Protoc Immunol 2008, Chapter 8, Unit 810.

24. Laroy W, Contreras R, Callewaert N: Glycome mapping on DNA sequencing equipment. Nat Protoc 2006, 1:397-405.

25. Zhang $W$, Inan $M$, Meagher MM: Rational design and optimization of fedbatch and continuous fermentations. Methods Mol Biol 2007, 389:43-64.

26. Kjeldsen T, Brandt J, Andersen AS, Egel-Mitani M, Hach M, Pettersson AF, Vad K: A removable spacer peptide in an alpha-factor-leader/insulin precursor fusion protein improves processing and concomitant yield of the insulin precursor in Saccharomyces cerevisiae. Gene 1996, 170:107-112.

27. Sinha J, Plantz BA, Zhang W, Gouthro M, Schlegel V, Liu CP, Meagher MM Improved production of recombinant ovine interferon-tau by mut(+) strain of Pichia pastoris using an optimized methanol feed profile. Biotechnol Prog 2003, 19:794-802.

28. Sinha J, Plantz BA, Inan M, Meagher MM: Causes of proteolytic degradation of secreted recombinant proteins produced in methylotrophic yeast Pichia pastoris: case study with recombinant ovine interferon-tau. Biotechnol Bioeng 2005, 89:102-112.

29. Potgieter TI, Cukan M, Drummond JE, Houston-Cummings NR, Jiang Y, Li F, Lynaugh H, Mallem M, McKelvey TW, Mitchell T, et al: Production of monoclonal antibodies by glycoengineered Pichia pastoris. J Biotechnol 2009, 139:318-325.

doi:10.1186/1475-2859-9-93

Cite this article as: Jacobs et al: Fed-batch fermentation of GM-CSFproducing glycoengineered Pichia pastoris under controlled specific growth rate. Microbial Cell Factories 2010 9:93.

\section{Submit your next manuscript to BioMed Central and take full advantage of:}

- Convenient online submission

- Thorough peer review

- No space constraints or color figure charges

- Immediate publication on acceptance

- Inclusion in PubMed, CAS, Scopus and Google Scholar

- Research which is freely available for redistribution 